Judith Saidel*

\title{
Smart Partnership in Contracting: Thriving in a Period of Intense Policy Uncertainty
}

https://doi.org/10.1515/npf-2017-0002

Abstract: The smart partnership framework introduced in this article is derived from extensive, on-site interviews with nonprofit and public contract managers conducted in several grounded research projects between 2011 and 2015 and from the research literature on contracting. The framework demonstrates the continuing explanatory power of resource dependence theory that disentangles the formidable influence of the public policy environment on organizational action. It is intended to provide a coherent guide for practice by enabling nonprofit managers in the social services field to navigate the current intense environmental uncertainty in which cross-sector contracting relationships between government agencies and nonprofit organizations are embedded. By providing an accessible way to understand an extraordinarily complex set of inter-organizational dynamics, the model offers a research-based definition and clear visualization of what it means to be a smart partner. It highlights the necessity of understanding the norms, expectations, structures, processes, and culture within which sector counterpart contract managers operate. Fundamental to the range of managerial strategies that the framework calls for is the need explicitly to attend to relationship building, to patterns of variation in relationships over time, and to their probable consequences. The integrative model consists of three inter-related organizational competencies and a number of secondary competencies. Competency 1: understand the dynamic nature of contracting relationships; secondary competencies: recognize predictable variations in relationships; comprehend the importance of multiple institutional logics. Competency 2: develop and sustain capacity for strategic adaptation; secondary competencies: build external and internal learning capacity; discern power shifts in inter-organizational relationships; maintain capability for strategic repositioning. Competency 3: participate proactively in shaping policy change; secondary competencies: attend to relationship development and nurturance; build trust and credibility.

*Corresponding author: Judith Saidel, Public Admin \& Policy, University at Albany Rockefeller College of Public Affairs and Policy, 135 Western Ave., Albany, NY 12222, USA,

E-mail: jsaidel@albany.edu 
Keywords: contracting, social services, policy environmental uncertainty, public governance

The link between the powerful influences of the public policy environment on organizational action has been a foundational tenet of the policy studies and organization theory literatures for many decades. As proposed in Pfeffer and Salancik's pioneering work The External Control of Organizations, A Resource Dependence Perspective (1978), policy engaged organizations both respond to and proactively work to alter the constraints and opportunities that the policy environment offers. Despite the near universal acceptance of this perspective, Pfeffer argued in the introduction to the Classic Edition of the volume (2003) that "... there is a limited amount of empirical work explicitly extending and testing resource dependence theory and its central tenets” (xvii). The smart partnership framework introduced in this article, derived from interviews conducted in several grounded research projects, responds to Pfeffer's challenge and corroborates the continuing explanatory power of the core components of resource dependence theory.

\section{Brief Overview of the Immediate Social Services Policy Environment}

Recently scholars have documented the remarkable scope of contracting for the delivery of publicly funded services as a major feature of public governance in the United States (Pettijohn et al. 2013). At the same time, especially in the field of social services, public policy at both the federal and state levels has moved out of many years of relative stability and into a period of heightened uncertainty and dramatic change. Given the recalibrated political equation in Washington-a Republican presidential administration and Republican control of both houses of Congress-efforts to enact significant changes in Medicaid policy are anticipated (Sperling 2016).

Among the states, major changes that involve the mandated implementation of Medicaid managed care into nontraditional health and social service areas are already under way (Allard and Smith 2014; Smith 2010). These state-level policy changes were described as "epochal," "monumental," and "historic" by three different nonprofit interviewees in a recent study (Saidel 2015a). One respondent observed, "This is a new paradigm ... that never happened before. 
This establishment of private insurance companies and managed care organizations as the intermediary between government and those of us who provide services, I think, is the biggest seminal change."

The smart partnership framework is intended to provide a coherent guide for practice by enabling nonprofit managers to navigate the current intense environmental uncertainty in which cross-sector contracting relationships between government agencies and nonprofit organizations are embedded. Based on data from studies conducted by the author over the last six years and the research literature on contracting, the integrative framework (see Figure 1) consists of three inter-related organizational competencies: (1) understand the dynamic nature of contracting relationships; (2) develop and sustain capacity for strategic adaptation; (3) participate proactively in shaping policy change. A number of secondary competencies, also included in the model, are explained later in the article. In an era in which inter-organizational and cross-sector contracting relationships are in unusual flux, the smart partnership model can serve to guide nonprofit managers as they both confront persistent environmental turbulence and respond to the remarkable opportunities that new conditions often entail.

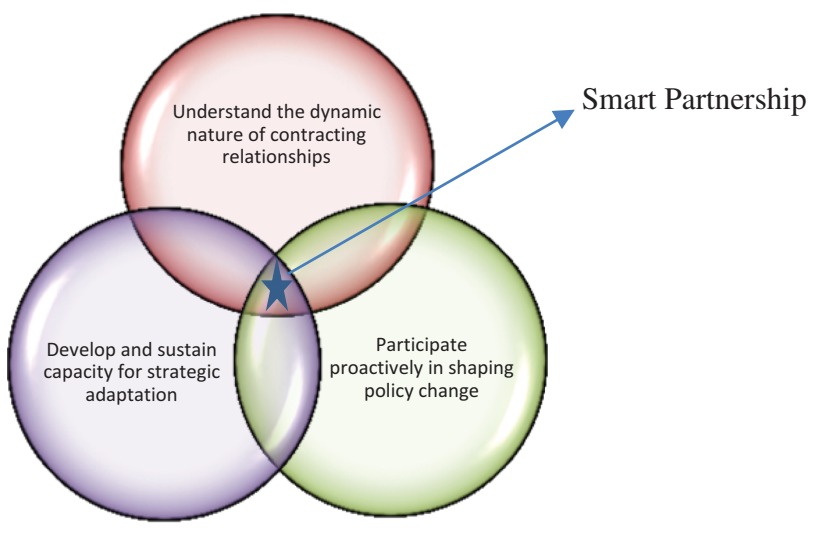

Figure 1: Smart partnership framework.

In the next section, the methodological basis for the framework's formulation in a series of the author's own research projects is briefly described. An explanation of the smart partnership framework's primary and secondary competencies follows. The conclusion draws out the value added by the framework to practice in a period of intense policy uncertainty. 


\section{Methodology}

A meta-analysis of 43 interviews, conducted in two separate research projects in 2012 and 2015, with public and nonprofit managers involved in contracting in New York State underpins the framework. In a 2012 interpretive, grounded research study (Saidel 2013, 2015b) the question was posed: How do public and nonprofit managers understand or interpret contracting interactions? Thirtyone respondents-14 nonprofit executives with contract management responsibilities in large to very large organizations and 17 public administrators from five social service state agencies-participated in in-depth, on-site, open-ended interviews.

In a new 2015 study, nonprofit executives described the ways in which they were responding to the "transformational shift," as one interviewee commented, in contracting policy related to Medicaid managed care (Saidel 2015a). In-depth, face-to-face semi-structured interviews were conducted with 12 nonprofit executives in the field of child welfare and behavioral health services. Leaders of long established (median year founded $=1852$ ) and very large nonprofits (median 2015 budget size $=\$ 37$ million), the respondents had been identified by state association executives as particularly innovative in circumstances of major pending but still uncertain policy changes. Reading and re-reading these 43 transcripts surfaced both explicit observations and implicit assumptions about the elements of an ideal model of contracting relationships in the contemporary turbulent world of public governance. The meta-analysis of interview data from both the 2012 study and the 2015 project conducted as Medicaid managed care was being rolled out enabled the formulation of the smart partnership framework.

\section{Smart Partnership Framework}

The term "smart partnership" builds on the foundation of the "smart buyer" construct, first utilized by Kettl (1993) in an important early public governance analysis (See also Van Slyke 2003). In surveying the increasing array of collaborative relationships involved in delivering public programs, he argued that "government must improve its capacity to act as a smart buyer or settle for ineffective programs" $(1993,194)$. Building on this conceptualization, the term "smart partner" shifts the focus from the procurement phase of contracting to its management. In addition, the term here applies to the nonprofit side of contract management. In this article, the meaning of smart partnership for nonprofit contract managers in the social services sub-sector is the focus of analysis. 


\section{Understand the Dynamic Nature of Contracting Relationships}

Underdeveloped theory related to the changing character over time of contracting relationships is a major challenge for both public governance theory and the individuals and organizations that function as governance actors. The secondary competencies of this element are especially important: recognize variations in contracting relationships; understand the importance of multiple institutional logics (see Table 1).

Table 1: Smart partnership primary and secondary competencies.

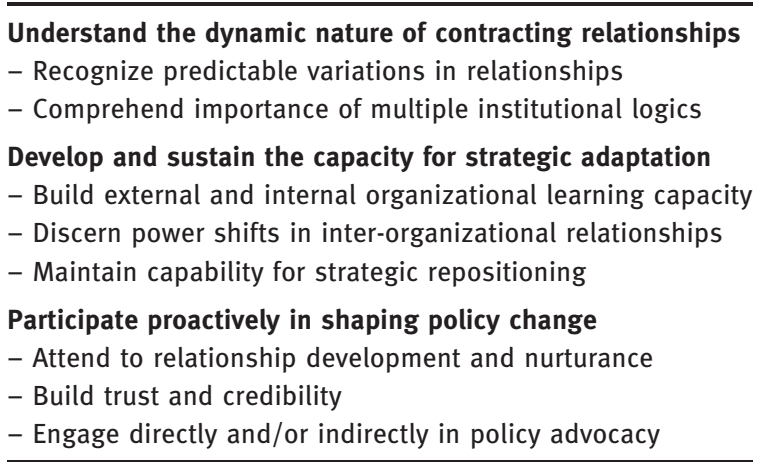

Recognize variation in relationships An important competency related to the first element of the framework is the necessity for nonprofit managers to understand patterns of relationships with government contracting agencies that are often in flux.

One way to understand variation in cross-sector contracting dynamics is as a governance continuum anchored by transactional principal-agent interactions at one end and relational interactions at the other end (Saidel 2011). The proxypartnership governance continuum (Figure 2) conceptualizes a broad range of fluid bilateral linkages that move between two poles anchored by governance by proxy or principal-agent interactions and governance by partnership or relational contracting interactions.

The primary characteristics of a principal-agent relationship are asymmetric information and potentially divergent goals between the principal (government agency) and agent (nonprofit organization) that result in the principal's need to provide incentives or establish significant monitoring procedures to curb opportunistic behavior by the agent. By contrast, relational contracting features 


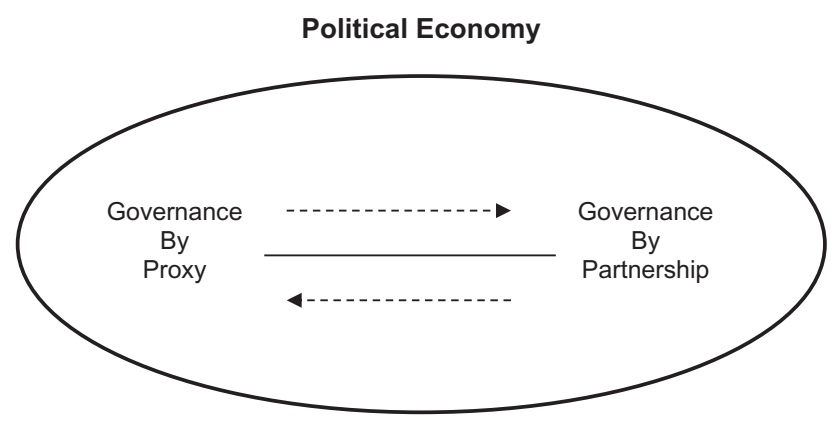

Figure 2: Proxy-partnership governance continuum.

interactions between contracting actors that are collaborative, flexible, nonadversarial, mutually problem-solving, and characterized by trust and frequent communications. Elements of both kinds of relationships are often apparent in the same set of inter-organizational linkages that are sometimes closer to the proxy end of the continuum and, at other times, closer to the partnership end.

Comprehend importance of multiple institutional logics. This competency calls for contracting actors in both government and nonprofits (and for-profit entities) to understand the institutional logic within which the other sectors operate. The term "institutional logic" is defined as including the regulatory framework, organizational structures, procedures and norms, and expectations of key stakeholders (Miltenberger 2013; Cairns and Harris 2011; Cooper 2003; DeHoog and Salamon 2002). According to Bryson, Crosby, and Stone, "Logics compete because actions, processes, norms, and structures that are seen as legitimate given one institutional logic may be seen as less legitimate or even illegitimate when one uses other logics" $(2015,10)$. How can deepened learning about the contexts and cultures of other sectors be accomplished? Higher education can play a role through graduate, certificate, and executive education programs. Joint learning workshops or more traditional within-agency training are other approaches.

\section{Develop and Sustain the Capacity for Strategic Adaptation}

The second element of the framework includes a subset of three key organizational competencies: (1) build external and internal organizational learning capacity; (2) discern power shifts in inter-organizational relationships; (3) maintain capability for strategic repositioning, or the capacity to develop alternative responses to strategic questions about fundamental identity and mission. 
Build external and internal organizational learning capacity The core elements of organizational learning or "absorptive capacity" (Zahra and George 2002)-fine-tuned attentiveness to and interpretation of environmental signals and information, diffusion of newly gleaned knowledge throughout the organization, and acting upon the new knowledge-were clearly described by respondents in my 2015a research project as strategies relied upon by nonprofit managers. One executive explained how he and another colleague were "listening to the potential shift of everything into managed care and realizing that we needed to do something differently than we had ever done before." Later in the interview he described a group, newly constituted within the organization, which was engaged in a "fairly intense learning process" through which environmental information was shared to "develop a sense of, program by program, what was going to be different and how we were going to make the change."

Virtually every nonprofit executive commented on the extraordinary investment of time spent to stay abreast of, absorb, and act upon the constantly changing flow of information that characterizes the system of Medicaid managed care being built as it is being implemented. Their observations underscore the substantial transaction and opportunity costs, long recognized by scholars and practitioners alike, associated with the contracting process. In addition, they reinforce the advantages of organization size in that larger organizations are more likely to have staff available to assign to organizational learning activities.

One manager noted the link between organizational learning and policy influence, thereby illustrating the overlap between dimensions of the smart partnership framework evident in Figure 1.

\footnotetext{
We then have been working very closely with [three state agencies] on an ongoing basis. We wanted to make sure that we were thoroughly educated on what was happening on the adult side with the changes and wanted to make sure that we were part of designing the new changes for the children's side.
}

Discern power shifts in inter-organizational relationships As shifts in resource exchanges occur between actors in bilateral contracting relationships, the relative balance of power between these actors also changes. Subsequently, efforts to restore balance or draw closer to a state of equilibrium can be expected. These efforts can be understood as strategic adaptations to power imbalances that often involve repositioning of the organization. Bryson, Crosby, and Stone $(2015,2006)$ urge those who lead collaboration efforts to recognize the power differentials inherent in their relationships and seek to lessen their impact where possible. One approach mentioned by 
several nonprofit executives involved repositioning the organization through a variety of moves to achieve enhanced standing and power in policy conversations with government officials. The observation below describes how an intentional expansion in organizational influence was achieved through the formation of new inter-organizational linkages among providers. Establishing affiliations and partnerships among agencies that had often been competitors for many years is a departure from past practice remarked on by a number of respondents. These new ties between nonprofits were explicitly designed to increase policy clout with both public and corporate decision-makers.

So this was our key strategy-to put ourselves in a leadership position with the State and with the other provider agencies that, linking together, we would create a strong position for children's services ... So that's been our strategy ... the first thing we did is try to set the big tables, make sure we're there and we're influencing all of that.

Maintain capability for strategic repositioning A third competency related to strategic adaptation involves the capability to develop alternative responses to the strategic questions "whom do we serve?" and "what services do we provide?" while remaining within or carefully modifying the boundaries of the organization's core mission. The strategies selected by interviewees often expanded the audiences served and programs offered. These changes depended on the availability of financial, human, and technical resources, a requirement that, again, advantages larger organizations. Several respondents emphasized that this potentially "slippery slope" must be undertaken in close consultation with the organization's board of directors and other relevant stakeholders as some adaptive actions can result in the kinds of mission drift and priority restructuring long noted by researchers (e. g. Saidel 1989; Smith and Lipsky 1993).

\section{Participate Proactively in Shaping Policy Change}

An overlapping theme that emerged from the 2015a interviews with nonprofit executives dealing with the dramatic policy changes in Medicaid managed care is the critical importance of participating in the policy change process. Dimensions of this component as well as the two others are the necessity of attending to relationship development and nurturance, building trust and credibility with public policy makers, especially in the administrative branch of government, and engaging directly and/or indirectly in policy advocacy.

Attend to relationship development and nurturance. In the study described earlier (Saidel 2015a), a nonprofit executive serving a large children's services 
agency emphasized the inter-related importance of both cultivating relationships and working jointly and consistently with public agency policy-makers by participating in the policy change process.

[We] wanted to make sure that we were part of designing the new changes for the children's side. This part is critical to our strategy because, if you wait 'til you develop your strategy until everything's formed and then you develop your strategy against what someone else created, it's likely to be not as successful. If you can actually help develop the state strategy in a way that you think fits what kids and families need for the future, then you're concurrently working out your organizational operational strategy against the overall state strategy for change.

Build trust and credibility. The importance of building trust and credibility between contracting actors has been documented in a number of recent studies (e. g. Van Slyke 2007; Alexander and Nank 2008; Bertelli and Smith 2010). In the smart partnership framework, both trust and credibility are complementary elements of productive working relationships.

\section{Engage Directly and/or Indirectly in Policy Advocacy}

Another respondent linked the necessity of ongoing organizational learning with simultaneous policy advocacy activities. He described two categories of externally directed efforts as "... the work we're doing externally to both educate ourselves to the emerging picture we have of the new environment and also to some degree the external work has to do with trying to influence the external environment." Organizational policy advocacy work occurs both individually and collectively, especially through the networks of intermediary membership associations operating at state and national levels.

\section{Conclusion}

Given that the smart partnership framework is intended to enable nonprofit managers to thrive in cross-sector contracting, this paper concludes with an examination of the ways in which this is accomplished. How does the model add value to practice? In what ways can the model guide nonprofit managers in contracting relationships with their government counterparts?

First, the model's research-based definition and clear visualization of what it means to be a smart partner provide an accessible way to understand an extraordinarily complex set of inter-organizational dynamics. Second, fundamental to the range of managerial strategies that the model calls for is the 
need explicitly to attend to relationship building, to patterns of variation in relationships over time, and to their probable consequences.

The model highlights the necessity of understanding the norms, expectations, structures, processes, and culture within which government contract managers operate. By understanding the realities of the multi-level governance dynamics under which their government contracting counterparts function, nonprofit managers can more easily anticipate changes in location of their contracting relationships along the proxy-partnership continuum and probable consequences of the shifts. For example, when governments confront significant budgetary shortfalls and government-nonprofit relationships move toward the proxy end of the continuum, nonprofit managers will recognize that the public managers with whom they interact will more often make decisions that are consistent with the vertical administrative and political dynamics that characterize government bureaucracies. Public contract managers will have less discretionary authority to share with providers and less opportunity to negotiate on matters like waivers or exceptions to regulatory requirements. They may also be less able to encourage innovative program initiatives advanced by nonprofit providers. They may share information less often and involve even trusted nongovernmental actors less frequently in agency decision-making processes. Under different circumstances, nonprofits may experience increases or decreases in the frequency and intensity of monitoring and enhanced or reduced access to bureaucratic policy-making.

By highlighting the dynamic character of contracting relationships including shifts in power among the players, the framework identifies additional political skills beyond negotiation and bargaining that nonprofit managers should cultivate. These skills include the political savvy to choose among alternative strategies directed toward public sector counterparts. Under what circumstances is it appropriate to intensify or lessen advocacy pressures? Under what circumstances should nonprofit managers lower expectations about the efficacy of bargaining and negotiation strategies and turn their attention to other approaches such as strategic repositioning options?

Third, the model deepens understanding of what strategic adaptation entails. It expands the meaning of and underscores the necessity of investing in organizational learning processes. Strong information gathering and environmental scanning capacities yield signals about impending shifts of power in interorganizational relationships, as well as potential repositioning strategies. The saliency of strong external information networks parallels the heightened need for more sophisticated internal information systems. Newly developed systems must both diffuse new perspectives about opportunities and constraints throughout the agency, and supply performance and outcome data to government officials and managed care organizations for whom accountability concerns are paramount. 
The smart partnership framework provides empirical evidence of the explanatory power of resource dependence and other theories that emphasize the strong linkages between the public policy environment and adaptive or challenging responses of organizations acting as policy players. It also expands the boundaries of applied contracting theory by providing an integrated model of nonprofit organizational competencies necessary for managing the changing dynamics of contracting relationships within an unusually turbulent and uncertain environment. Further empirical work, now under way, will incorporate the perspectives of government managers involved in contracting processes.

Acknowledgements: I would like to thank Professors Hillel Schmid and Michal Almog-Bar and the other participants in the June 2016 Workshop on "Civil Society and the Welfare State in the Age of New Public Governance: A CrossNational Exploration," Hebrew University of Jerusalem, for their valuable comments on an earlier, longer version of this paper. I also acknowledge the valuable comments of Elizabeth Boris, Tim Delaney, other participants in the 2016 ARNOVA Nonprofit Public Policy Symposium, and the anonymous reviewers of this manuscript.

\section{References}

Alexander, J., and R. Nank. 2008. "Public Nonprofit Partnership: Realizing the New Public Service." Administration and Society 41 (3):364-386.

Allard, S. W., and S. R. Smith. 2014. "Unforeseen Consequences: Medicaid and the Funding of Nonprofit Service Organizations." Journal of Health Politics, Policy and Law 39 (6):1135-1172.

Bertelli, A., and C. R. Smith. 2010. "Relational Contracting and Network Management." Journal of Public Administration Research and Theory Special Issue "The State of Agents." 20:i21-i40.

Bryson, J. M., B. C. Crosby, and M. M. Stone. 2015. 2006. "The Design and Implementation of Cross-Sector Collaborations: Propositions from the Literature. Special Issue.” Public Administration Review 66:44-55.

Bryson, J. M., B. C. Crosby, and M. M. Stone. 2015. "Designing and Implementing Cross-Sector Collaborations: Needed and Challenging." Public Administration Review 75 (5):1-16. Published online August 9, 2015. doi:10.1111/puar.12432.

Cairns, B., and M. Harris. 2011. "Local Cross-Sector Partnerships: Tackling the Challenges Collaboratively." Nonprofit Management and Leadership 21 (3):311-324.

Cooper, P. J. 2003. Governing by Contract, Challenges and Opportunities for Public Managers. Washington, DC: CQ Press.

DeHoog, R. H., and L. M. Salamon. 2002. "Purchase-of-Service Contracting." In The Tools of Government, A Guide to the New Governance, edited by L. M. Salamon, 319-339. Oxford: Oxford University Press. 
Kettl, D. F. 1993. Sharing Power, Public Governance and Private Markets. Washington, DC.: Brookings Institution.

Miltenberger, L. 2013. “Collaboration, Contracting, and Contradictions: How Nonprofit Leaders Can Begin to Think about Collaborating with Government." Journal of Leadership Studies 7 (1):54-60.

Pettijohn, S. L., E. T. Boris, C. J. DeVita, and S. D. Fyffe. 2013. Nonprofit-Government Contracts and Grants: Findings from the 2013 National Survey. Washington, DC: The Urban Institute. http://www.urban.org/publications/412962.html.

Pfeffer, J. 2003. “Introduction to the Classic Edition." In The External Control of Organizations, $A$ Resource Dependence Perspective, edited by J. Pfeffer and G. R. Salancik, (originally 1978), xi-xxix. New York: Harper \& Row.

Saidel, J. R. 1989. "Dimensions of Interdependence: The State-Voluntary Sector Relationship." Nonprofit and Voluntary Sector Quarterly 18 (4):335-347.

Saidel, J. R. 2011. "The Proxy-Partnership Governance Continuum: Implications for Nonprofit Managers." In The State of Public Administration: Issues, Challenges, and Opportunities, edited by D. C. Menzel and H. L. White. Armonk, NY: M.E. Sharpe.

Saidel, J. R. 2013. “Nonprofit Managers as 'Smart Partners:' Contracting Practices in an Age of Turbulence." Paper presented at the Annual Conference of the Association for Research on Nonprofit Organizations and Voluntary Action. Hartford, CT, November 20-23.

Saidel, J. R. 2015a. Innovative Nonprofit Strategies for Cross-Boundary Contract Management. Paper prepared for presentation at the Annual Conference of the Association for Research on Nonprofit Organizations and Voluntary Action. Chicago, IL, November 18-21.

Saidel, J. R. 2015b. "Relational Contracting and Public Value: Public and Nonprofit Managers' Perspectives." In Creating Public Value in Practice, edited by J. M. Bryson, B. C. Crosby and L. Bloomberg, 203-224. Boca Raton, FL: CRC Press.

Smith, S. R. 2010. "Managing the Challenges of Government Contracts." In The Jossey-Bass Handbook of Nonprofit Leadership and Management, edited by D. O. Renz and Associates, 553-579. San Francisco, CA: Jossey-Bass.

Smith, S. R., and M. Lipsky. 1993. Nonprofits for Hire, the Welfare State in the Age of Contracting-. Cambridge, MA: Harvard University Press.

Sperling, G. B. 2016. The Quiet War on Medicaid. New York Times. December 27.

Van Slyke, D. M. 2003. "The Mythology of Privatization in Contracting for Social Services." Public Administration Review 63 (3):296-315.

Van Slyke, D. M. 2007. "Agents or Stewards: Using Theory to Understand the GovernmentNonprofit Social Service Contracting Relationship." Journal of Public Administration Research and Theory 17 (September):157-187.

Van Slyke, David M. 2009. "Collaboration and Relational Contracting." In The Collaborative Public Manager, edited by Rosemary O'Leary and Lisa B. Bingham. Washington, DC: Georgetown University Press, 137-156.

Zahra, S. A., and G. George. 2002. "Absorptive Capacity: A Review, Reconceptualization, and Extension.” Academy of Management Review 27 (2):185-203. 